\title{
Gastrin-17 Levels in Pre-malignancy Gastritis Lesions
}

Authors:

Disclosure:

Acknowledgements:

Received:

Accepted:

Keywords:

Citation:
*Sahat Halim, Gontar Alamsyah Siregar

Department of Internal Medicine, Faculty of Medicine, University of Sumatera Ultara, Medan, Indonesia

*Correspondence to sahathalim88@gmail.com

The authors have declared no conflicts of interest.

The authors gratefully acknowledge that the present research is supported by the Ministry of Research and Technology and the Higher Education Republic of Indonesia. The support is under the research grant TALENTA, Contract Number: 363 UN5.2.3.1/ PPM/SP-TALENTA USU/2020. Author contribution: All authors were involved in planning and supervising the work, processing the data, performing the analysis, drafting the manuscript, designing the figures, calculations and statistical analysis, discussing the results, and commenting on the manuscript.

28.07.21

28.09.21

Gastrin, gastritis, pre-malignant.

EMJ Gastroenterol. 2022; DOI/10.33590/emjgastroenterol/21-00156.

https://doi.org/10.33590/emjgastroenterol/21-00156

\section{Abstract}

Background: Gastritis is an inflammatory process on the lining of the stomach that could be caused by various factors. Untreated inflammatory processes could lead to ulcers. Gastrin hormone is released by gastrin-secreting enteroendocrine cells (G cells) in the stomach, which influence the secretion of gastric acid and helps the proliferation of gastric epithelial cells. Its abnormal secretion in $H$. pylori infection, with food-stimulated excessive release of gastrin, is the most prominent abnormality. One concern is the relationship of excess gastrin secretion to the incidence of gastric cancer. This study aimed to show the difference in gastrin levels on patients with gastritis, both with and without pre-malignant lesions.

Methods: This research was a cross-sectional study with 40 samples that had met the inclusion and exclusion criteria. Endoscopy was performed to assess the gastric mucosa and tissue biopsy was performed afterward. The data was analysed in univariate and bivariate ways.

Results: From this study, 20 people were positive for pre-malignant lesions (50\%). MannWhitney test analysis was used to analyse the data and showed there was a significant difference between gastrin levels on patients with gastritis with and without pre-malignant lesions, with a $p$ value of 0.01 .

Conclusion: There is a significant difference between gastrin levels in patients with gastritis with and without pre-malignant lesions, which could be the basis for early detection of patients with gastric cancer. 


\section{INTRODUCTION}

Gastritis is an inflammatory process on the lining of the stomach that is quite frequent and can have various causes. Various types of agents can cause gastritis, including painkillers, abrasive compounds (such as alcohol, acids, etc.), an unbalanced diet where the stomach will be damaged by the stomach acid itself, longterm physical or mental stress that can cause excessive production of gastric acid, as well as an infection caused by a micro-organism, namely Helicobacter pylori. When this inflammation is left untreated, it can eventually become ulcers or, at worst, gastric cancer.

The interaction of $\mathrm{H}$. pylori with the gastric mucosa activates several body responses including the release of inflammatory factors, some ILs, TNF-a, and leukotriene, which is cytotoxic to the gastric epithelium. This inflammatory response causes changes in the function of the stomach, depending on the location in the stomach involved. When inflammation involves the gastric corpus, parietal cells are inhibited thereby reducing gastric acid secretion. If this inflammation continues, the parietal cells continue to experience damage so that the reduction in acid secretion is permanent. ${ }^{1,2}$

Inflammation of the antrum changes the interplay of gastrin with somatostatin, affecting $G$ cells (cells that secrete gastrin) and D cells (cells that produce somatostatin), in reverse. Specifically, gastrin secretion is abnormal in $\mathrm{H}$. pylori infection, with food-stimulated excessive release of gastrin being the most prominent abnormality. ${ }^{2}$

Gastrin is an important growth factor for the development of the digestive system. Gastrin is released from $\mathrm{G}$ cells in the antrum of the stomach during normal physiological digestion of food and serves as the main stimulator of acid secretion from the parietal cells of the stomach. ${ }^{3}$

One of the main concerns regarding hypergastrinaemia is the potential link between gastrin level and gastric cancer. When gastrin was administered to animals, there was a marked increase in the mass of parietal cells and enterochromaffin-like (ECL) cells from the stomach. Increased levels of gastrin in mice and humans have been associated with gastric carcinoid tumours arising from ECL cells. In cell culture, gastrin has been shown to stimulate the growth of the cancerous cell lining in the human stomach. ${ }^{3}$

Approximately 700,000 deaths in the world are caused by gastric cancer; therefore, gastric cancer is the second most common cancer causing death. ${ }^{4}$ Gastric carcinogenesis is an ongoing process. The majority of cases of gastric cancer are preceded by atrophic events. ${ }^{5}$ Chronic atrophic gastritis is an important precursor lesion in the development of gastric cancer. The natural course of gastric cancer is known as the Correa cascade; ${ }^{6}$ according to the Correa cascade, prolonged mucosal inflammation can cause the gastric mucosa to atrophy, which can lead to invasive cancer.

Thus, this study was carried out to determine the association of gastrin levels in patients with gastritis with or without pre-malignant lesions.

\section{METHODS}

This research was a cross-sectional study. Subjects were patients who came to $\mathrm{H}$. Adam Malik Hospital, Medan, Indonesia, and the General Hospital of North Sumatera, Indonesia, with chronic abdominal pain and discomfort with a high pre-test probability of gastritis. The data were collected from March to October 2020. All patients underwent endoscopic and histopathological examination, then were categorised into patients with or without premalignant gastric lesions. The inclusion criteria were minimum age 18 years and agreement to take part. Exclusion criteria were pregnancy, and systemic diseases such as diabetes, liver disease, renal disease, heart disease, and malignancy. Patients who were on chronic proton pump inhibitors and $\mathrm{H}$ 2-antagonist receptors had stopped their medication for at least 10 days. The patients were not allowed to medicate at all or switch to other medication such as antacids or rebamipide.

Endoscopy was performed to assess the presence of any pre-cancerous lesion in the stomach, such as gastric atrophy, chronic gastritis, metaplasia, and dysplasia. All subjects were checked for gastrin level using the ELISA Human Gastrin-17 Kit (BIOHIT OYJ, Laippatie, Fl-00880, Helsinki, Finland), which was examined in Prodia Laboratory, Surakarta, Indonesia. 
Data analysis was performed in univariate and bivariate analysis (Mann-Whitney test) using SPSS ${ }^{\circledR} 22^{\text {nd }}$ version (SPSS Inc., Chicago, Illinois, USA). A value of $p<0.05$ was considered statistically significant.

\section{RESULTS}

\section{Characteristics of Clinical and Socio- demographic Subjects}

A total of 40 patients were enrolled in this study (Table 1). There were 22 male (55\%) and 18 female (45\%) subjects of study. The mean age was 53 years, with ages ranging from 30 to 68 years.

Based on endoscopic examination, 20 subjects (50\%) had positive pre-malignant lesions. The mean value of gastrin blood level was $15.4(0.4-50.4) \mathrm{pmol} / \mathrm{mL}$ among all subjects.

\section{Difference in Gastrin Level in Patients With Gastritis With and Without Pre- malignant Lesions}

Shapiro-Wilk normality test showed that the data in this study were not normally distributed $(p<0.05)$. Table 2 shows the result of the MannWhitney statistical test. There was a significant difference between gastrin levels in patients with gastritis with and without pre-malignant lesions.

Because $p<0.05 \quad(p=0.01)$, the alternative hypothesis is accepted.

As seen in Table 3, the overall average level of gastrin in all subjects was $15.02 \mathrm{pmol} / \mathrm{mL}$, with a minimum level of $0.4 \mathrm{pmol} / \mathrm{mL}$ and a maximum level of $50.4 \mathrm{pmol} / \mathrm{mL}$. Gastrin levels in patients with gastritis with pre-malignant lesions showed a higher average $(21.33 \mathrm{pmol} / \mathrm{mL})$. The average gastrin level was $8.72 \mathrm{pmol} / \mathrm{mL}$ in patients with gastritis without pre-malignant lesions.

Table 1: Clinical and socio-demographic characteristics of research subjects.

\begin{tabular}{|l|l|}
\hline Variable & N=40 \\
\hline Sex & $22(55 \%)$ \\
\hline Male & $18(45 \%)$ \\
\hline Female & $53(30-68)$ \\
\hline Age (years) & $5(12.5 \%)$ \\
\hline Age group (years) & $3(7.5 \%)$ \\
\hline $30-39$ & $21(52.5 \%)$ \\
\hline $40-49$ & $11(27.5 \%)$ \\
\hline $50-59$ & \multicolumn{2}{|l|}{} \\
\hline$>60$ & $20(50 \%)$ \\
\hline Ethnicity & $16(40 \%)$ \\
\hline Bataknese & $2(5 \%)$ \\
\hline Javanese & $2(5 \%)$ \\
\hline Acehnese & \multicolumn{2}{|l|}{} \\
\hline Nias & $20(50 \%)$ \\
\hline Pre-malignant lesions & $20(50 \%)$ \\
\hline Positive & 15.02 \\
\hline Negative & 0.4 \\
\hline Gastrin levels (pmol/mL) & 50.4 \\
\hline Mean & \\
\hline Minimum & \\
\hline Maximum & \\
\hline & \\
\hline
\end{tabular}




\begin{tabular}{|l|l|l|}
\hline Pre-cancer lesion & Gastrin-17 (mean ranks) & p \\
\hline Positive & 26.45 & 0.01 \\
\hline Negative & 14.55 & N/A \\
\hline
\end{tabular}

\section{DISCUSSION}

Gastrin is a peptide hormone primarily responsible for enhancing gastric mucosal growth, its motility, and the secretion of hydrochloric acid into the stomach, and is produced by $G$ cells. Both the antrum and duodenum have $G$ cells ( $G-17$ and $G-34$ ) that function to produce gastrin. Its secretion into the systemic circulation allows delivery of gastrin to parietal cells and ECL cells in the gastric fundus and cardiac. Gastrin then stimulates the proliferation of gastric mucosal endocrine cells such as parietal cells. ${ }^{7,8}$

A total of 40 patients with gastritis were enrolled in this study. Twenty-two were male, with the highest gastritis rate in the age group 50-59 years, but there was no statistical significance. The average serum gastrin level in this study was $15.02 \mathrm{pmol} / \mathrm{mL}$. Histopathological examination showed 20 subjects with a premalignant lesion, with minimum gastrin level in this group of $3.0 \mathrm{pmol} / \mathrm{mL}$. Other research by Wang and Chen ${ }^{9}$ also found a similarly high level of gastrin was associated with pre-cancerous lesions and gastric cancer in Asian populations. Their study stated that the prevalence of atrophic gastritis tended to increase from benign to malignant lesions.

Lesions such as atrophy might decrease acid secretion, while gastrin would increase through the acid feedback adjustment. In addition, the use of a proton pump inhibitor could also inhibit acid secretion leading to the elevated levels of gastrin. ${ }^{9}$

Based on this statistical study, the authors found a significant difference between gastrin levels on the incidence of gastritis with and without premalignant lesions. In the present study, gastrin level tended to be higher in subjects with premalignant lesions; other studies showed some similar and some varied findings (Table 4). A study by Shafaghi et al. ${ }^{10}$ showed a significant difference in gastrin blood level in patients with atrophy or metaplasia compared to patients without $(p<0.05)$. The study also showed that gastrin had fair sensitivity (59\%) and specificity (61\%) in diagnosing pre-malignant gastric lesions. ${ }^{10}$

Another study by Murphy et al. ${ }^{11}$ showed that study subjects with elevated gastrin levels had an increased risk of gastric non-cardia adenocarcinomas (odds ratio: 1.92; 95\% confidence interval: 1.21, 3.05). ${ }^{11}$ A study by Soumyodhriti et al. ${ }^{12}$ showed that serum gastrin was found to be elevated in all 30 patients who were planned to undergo gastric resection. This study also concluded that serum gastrin serves as a marker for diagnosis of gastric cancer but

Table 3: Gastrin level differences in patients with gastritis (pmol/mL).

\begin{tabular}{|l|l|l|l|l|l|}
\hline & N & Mean & Median & SD & Min-max \\
\hline Whole study population & 40 & 15.02 & 10.5 & 15.22 & $0.4-50.4$ \\
\hline With pre-malignant lesion & 20 & 21.33 & 18.1 & 15.75 & $3.0-48.3$ \\
\hline Without pre-malignant lesion & 20 & 8.72 & 2.7 & 11.99 & $0.4-50.4$ \\
\hline
\end{tabular}


Table 4: Comparison of studies assessing gastrin levels.

\begin{tabular}{|c|c|c|c|}
\hline & \multicolumn{3}{|c|}{ Gastrin level (pmol/mL) } \\
\hline \multicolumn{4}{|l|}{ Present study } \\
\hline & \multicolumn{2}{|c|}{ Pre-malignant lesions } & Malignant lesions \\
\hline Mean (based on group) & \multicolumn{2}{|l|}{8.72} & 21.33 \\
\hline Overall mean (min-max) & \multicolumn{3}{|l|}{$15.02(0.40-50.40)$} \\
\hline$p$ value & \multicolumn{3}{|l|}{0.01} \\
\hline \multicolumn{4}{|l|}{ Shafaghi et al., ${ }^{10} 2013$} \\
\hline & Atrophic gastritis & Metaplasia & Dysplasia \\
\hline Mean (SD) & $6.31(10.73)$ & $5.96(9.58)$ & $5.96(6.76)$ \\
\hline$p$ value & $<0.001$ & 0.005 & 0.050 \\
\hline \multicolumn{4}{|l|}{ Murphy et al.,"1 2017} \\
\hline & Control & \multicolumn{2}{|l|}{ GNCA } \\
\hline Median & 13.9 & \multicolumn{2}{|l|}{17.0} \\
\hline \multicolumn{4}{|c|}{ Nejadi-Kelarijani et al., ${ }^{13} 2014$} \\
\hline & Non-atrophic & Atrophic & Gastric cancer \\
\hline Mean \pm SE & $13.82 \pm 1.7$ & $8.32 \pm 1.6$ & $10.81 \pm 2.8$ \\
\hline$p$ value & \multicolumn{3}{|l|}{0.34} \\
\hline
\end{tabular}

GNCA: gastric non-cardia adenocarcinomas; max: maximum; min: minimum; SD: standard deviation; SE: standard error.

was not necessarily associated with an advanced stage of disease. ${ }^{12}$

Contradicting the previous studies, a study by Nejadi-Kelarijani et al. ${ }^{13}$ showed that gastrin-17 blood level was higher in non-atrophic gastritis $(13.82 \pm 1.7 \mathrm{pmol} / \mathrm{L})$ compared to atrophic gastritis $(8.32 \pm 1.6 \mathrm{pmol} / \mathrm{L})$ and gastric cancer (10.81 \pm 2.8 $\mathrm{pmol} / \mathrm{L})$, although this result was insignificant $(p=0.34) .^{13}$ Overall, shreds of evidence imply gastrin levels are higher in pre-malignant gastric lesions. The study by Handayani and Krisnuhoni ${ }^{14}$ showed that atrophy of the gastric body is a condition marked by the existence of atrophy of the oxyntic mucosa, which leads to hyposecretion of gastric acid, sending negative feedback to increase gastrin levels, which also increases the risk for neoplasm in the stomach. ${ }^{14}$

A study by Song et al. ${ }^{15}$ showed that one in 256 patients with normal mucosa, one in 85 patients with gastritis, one in 50 patients with atrophic gastritis, one in 39 patients with intestinal metaplasia, and one in 19 patients with dysplasia, will develop gastric cancer within 20 years; in Cox regression analyses, hazard ratios also incrementally increased with successive cascade stage, from 1.8 for minor mucosal change to 10.9 for dysplasia. ${ }^{15}$

A study by Yanaoka et al..$^{5}$ showed that among 5,209 participants who were followed up to 10 years, 63 cases of cancer developed in the cohort, representing an incidence rate of 125 per 100,000 person-years. The cancer incidence rate was 276 per 100,000 person-years for the atrophypositive group and 70 per 100,000 person-years for the atrophy-negative group. ${ }^{5}$ These findings implicate the importance of managing patients with gastritis, as there are still possibilities for benign gastritis to evolve into malignant lesions.

According to a guideline released by the European Society of Gastrointestinal Endoscopy (ESGE), all patients with atrophic gastritis with or without dysplasia should undergo screening for malignancy and $H$. pylori eradication management. Patients without dysplasia should be followed-up and re-evaluated every 3 years. Patients with low-grade dysplasia can be 
evaluated every 12 months, while patients with high-grade dysplasia should be evaluated every 6-12 months, and when a visible lesion appears on endoscopic examination undergo staging and resection surgical management. ${ }^{16}$

\section{LIMITATIONS}

The authors are fully aware that this study had several limitations. The study sample number was small, which related to limited funding and resource problems. There was no follow-up period, so the authors cannot conclude whether the subjects developed malignant gastric cancer. The authors also only took one-time blood measurements, thus damaged or inadequate blood samples and errors in blood extraction procedure were a possibility. All the subjects had a history of proton pump inhibitor or H2histamine antagonist medications, which can result in bias of gastrin blood level.

\section{CONCLUSION}

A total of 40 patients with gastritis were enrolled in this study. From this study, the authors found a significant difference between gastrin level in patients with gastritis with and without premalignant lesions. This finding could be the basis of further research in gastrin uses for screening in patients with a risk of developing gastric cancer.

\section{References}

1. Tonino P (ed.), Gastritis and Gastric Cancer: New Insights in Gastroprotection, Diagnosis, and Treatments (2011), London: InTech Open.

2. Marcus AJ. Chronic Gastritis. Medscape. 2017. Available at: https://emedicine.medscape. com/article/176156-overview. Last accessed: 1 February 2020.

3. Smith JP et al. Gastrin and gastric cancer. Cell Mol Gastroenterol Hepatol. 2017;4(1):75-83.

4. Parkin DM et al. Global cancer statistics, 2002. CA Cancer J Clin. 2005;55(2):74-108.

5. Yanaoka $\mathrm{K}$ et al. Cancer highrisk subjects identified by serum pepsinogen tests: outcomes after 10-year follow-up in asymptomatic middle-aged males. Cancer Epidemiol Biomarkers Prev. 2008;17(4):838-45.

6. Ohata $\mathrm{H}$ et al. Progression of chronic atrophic gastritis associated with Helicobacter pylori infection increases risk of gastric cancer. Int J Cancer. 2004;109(1):138-43.

7. Prosapio JG et al. Physiology, Gastrin 2021. Available at: https://www.ncbi. nlm.nih.gov/books/NBK534822/. Last accessed: 1 February 2020.

8. Mattar R et al. Diagnosis accuracy of GatroPanel for atrophic gastritis in Brazilian Subjects and the effect of Proton Pump Inhibitor. Arq Gastroenterol. 2020;57(2):154-160.

9. Wang $R$ Chen $X Z$. Prevalence of atrophic gastritis in southwest China and predictive strength of serum gastrin-17: a cross-sectional study (SIGES). Sci Rep. 2020;10(1):4523.

10. Shafaghi A et al. Serum gastrin and the pepsinogen I/II ratio as markers for diagnosis of premalignant gastric lesion. Asian Pac J Cancer Prev. 2013;14(6): 3931-6.

11. Murphy $\mathrm{G}$ et al. Serum gastrin and cholecystokinin are associated with subsequent development of gastric cancer in a prospective cohort of Finnish smokers. Int J Epidemiol. 2017;46(3): 914-23.

12. Soumyodhriti $\mathrm{G}$ et al. Serum gastrin level estimation, is it a prognostic indicator in operated carcinoma stomach patients? Sch J App Med Sci. 2016;4(4B):1208-11.

13. Nejadi-Kelarijani $F$ et al. Diagnostic values of serum levels of pepsinogens and gastrin-17 for screening gastritis and gastric cancer in a high-risk area in northern Iran. Asian Pac J Cancer Prev. 2014;15(17):7433-6.

14. Handayani L, Krisnuhoni E. Demographic characteristic of fundic gland polyp and its association with gastritis in pathology, Anatomy Department Faculty of Medicine, University Indonesia/ Cipto Mangunkusumo Hospital. 2017. Available at: https://media.neliti. com/media/publications/196231demographic-characteristic-offundic-gla-3bb4a183.pdf. Last accessed: 4 October 2021.

15. Song $\mathrm{H}$ et al. Incidence of gastric cancer among patients with gastric precancerous lesions: observational cohort study in a low-risk Western population. BMJ. 2015;351:h4134.

16. Dinis-Ribeiro $M$ et al. Management of precancerous conditions and lesions in the stomach (MAPS): guideline from the European Society of Gastrointestinal Endoscopy (ESGE), European Helicobacter Study Group (EHSG), European Society of Pathology (ESP), and the Sociedade Portuguesa de Endoscopia Digestiva (SPED). Endoscopy. 2012;44(1):74-94. 